\title{
O Pensamento Computacional no Ensino Superior e seu Impacto na Aprendizagem de Programação
}

\author{
Emanuel Leite Oliveira da Silva ${ }^{1}$, Taciana Pontual Falcão ${ }^{2}$ \\ ${ }^{1,2}$ Departamento de Computação, Universidade Federal Rural de Pernambuco (UFRPE) \\ Campus Dois Irmãos, Recife-PE \\ ${ }^{1}$ silva.oliveira.emanuel@gmail.com, ${ }^{2}$ taciana.pontual@ufrpe.br
}

\begin{abstract}
The consolidation of Computational Thinking $(C T)$ as an essential ability of the contemporary citizen has been leading to new guidelines at all levels of Brazilian education. In higher education in Computing, the development of CT adds up to approaches that aim at overcoming difficulties in teaching and learning programming, and consequently reducing failure and dropout rates. In this paper, based on insights from exploratory field research, we argue that there is still a lot to debate about how to best integrate CT to curricula, in particular of teacher education courses, in ways that meet the new expected standards for educators, but also develops their CT ability and facilitates their learning of programming.
\end{abstract}

Resumo. A consolidação do Pensamento Computacional (PC) como habilidade essencial do cidadão contemporâneo vem se refletindo em novas diretrizes $e$ referenciais em todos os níveis da educação brasileira. Nos cursos superiores de computação, o desenvolvimento do PC vem se somar às abordagens que visam a superação de dificuldades no ensino e aprendizagem de programação, e a consequente redução da retenção e evasão. Neste artigo, a partir de insights de uma pesquisa de campo exploratória, argumentamos que ainda há muito a debater sobre como integrar o PC aos currículos, em particular dos cursos de Licenciatura em Computação, de forma a contemplar a formação esperada deste educador alinhada às novas tendências, mas também desenvolver sua habilidade de PC, e facilitar a aprendizagem de programação.

\section{Introdução}

A evasão, no contexto do ensino superior, pode ser definida como "a saída definitiva do aluno de seu curso de origem, sem concluí-lo" (MEC, 1996, p.15). Cursos de computação têm, historicamente, altos índices de evasão, sendo um dos motivos as dificuldades com programação (SBC, 2017; HOED, 2016). Uma recente revisão sistemática realizada nas bases de dados de educação em computação no Brasil indica que as principais habilidades consideradas por educadores como necessárias à aprendizagem de programação são: raciocínio lógico (citado em $24 \%$ dos 84 artigos analisados), abstração (15\%), noções matemáticas (14\%) e resolução de problemas (13\%). Por outro lado, $25 \%$ dos artigos indicam que os estudantes de computação 
apresentam como maiores dificuldades: resolução de problemas (25\%); abstração (21\%), e raciocínio lógico e algorítmico (12\%) (MEDEIROS, 2019).

Neste sentido, uma habilidade que vem ganhando atenção em pesquisas que buscam amenizar as dificuldades de aprendizagem de programação é o Pensamento Computacional (PC), que se baseia em lógica algorítmica e outros conceitos da computação como abstração, decomposição e avaliação, visando a resolução de problemas (WING, 2006). Nos Referenciais de Formação para os Cursos de Graduação em Computação da Sociedade Brasileira de Computação (SBC), o PC aparece como uma competência esperada (ZORZO et al., 2017), e já existem disciplinas com foco em PC no ensino superior (PONTUAL FALCÃO et al., 2018), assim como uma forte mobilização de órgãos nacionais e internacionais pela introdução do PC na educação básica como a $\operatorname{ISTE}^{1}$ e $\mathrm{CIEB}^{2}$.

Entretanto, ainda não existem dados sobre o impacto que o desenvolvimento do PC pode ter na aprendizagem de programação no ensino superior. Assim, na presente pesquisa, realizou-se uma investigação preliminar, qualitativa e exploratória, no contexto dos cursos de Licenciatura em Computação (LC) que contam com disciplinas de PC em sua matriz curricular, para investigar se a aplicação do PC no ensino superior traz benefícios ao aprendizado de programação (dos pontos de vista cognitivo e afetivo).

\section{Método}

A pesquisa foi realizada com estudantes e professores de cursos de LC cuja matriz curricular contém a disciplina de PC. A escolha pelos cursos de LC baseou-se na tendência de introdução do PC na educação básica (como preconizado por órgãos como ISTE e CIEB), que vem gerando mudanças nos currículos de LC para, por um lado, desenvolver esta habilidade nos licenciandos, e por outro lado, formá-los para atuar com PC na educação básica.

Foram contatadas por e-mail institucional as coordenações de cursos de LC de sete (07) institutos federais e nove (09) universidades federais, com a disponibilização de duas versões de um questionário online (Google Forms): uma para estudantes que tiveram contato com PC no semestre anterior ao que cursaram Programação (perfil P1); e outra para aqueles que só tiveram contato com PC após cursarem Programação (perfil P2). O questionário contemplava tópicos referentes aos receios relacionados ao aprendizado de programação; o sentimento de estar ou não preparado para aprender programação; a autoavaliação sobre as habilidades de raciocínio lógico e pensamento algorítmico; e a percepção sobre o PC. Ao responder o questionário, os estudantes forneceram também consentimento livre e esclarecido para que os dados fossem usados na pesquisa.

Além dos questionários aos estudantes, foram entrevistados, de maneira semi-estruturada, dois professores de Programação do curso de LC da Universidade Federal Rural de Pernambuco (UFRPE), onde desde o segundo semestre letivo de 2018,

\footnotetext{
${ }^{1}$ ISTE. Standards for Students. International Society for Technology in Education, 2016. Disponível em: https://www.iste.org/standards/for-students

${ }^{2}$ CIEB. Currículo de Referência em Tecnologia e Computação. Centro de Inovação para a Educação Brasileira, 2018. Disponível em: http://curriculo.cieb.net.br/
} 
consta a disciplina de Pensamento Computacional, no primeiro período do curso, sendo pré-requisito para Programação (PONTUAL FALCÃO et al., 2018). Os professores foram entrevistados sobre suas primeiras impressões acerca do desempenho dos estudantes após a introdução do PC na matriz curricular.

\section{Resultados}

Recebemos respostas de estudantes de seis (06) das dezesseis (16) instituições contatadas, a saber: institutos federais do Rio Grande do Norte (IFRN) e Triângulo Mineiro (IFTM); e universidades federais do Paraná (UFPR), Bahia (UFBA), Sul da Bahia (UFSB) e Rural de Pernambuco (UFRPE). Foram 20 estudantes do perfil P1 e 26 do perfil P2.

Dentre os 46 respondentes, 20 estudantes declararam terem tido receio de cursar programação antes de começar a disciplina. Dentre os 20 respondentes do perfil P1, 19 concordaram que o contato com PC aumentou sua confiança e deixou-os mais preparados para aprender programação. No campo aberto para comentários, um dos respondentes afirmou que "com pensamento computacional ficou fácil entender lógica de programação, e com isso, ficou tudo mais fácil aprender programação".

Especificamente em relação aos níveis de raciocínio lógico e pensamento algorítmico, 18 (de 20) respondentes P1 e 20 (de 26) respondentes P2 concordaram que o PC contribuiu para a sua melhoria. A Figura 1 mostra a auto-avaliação dos 46 respondentes sobre seu raciocínio lógico e pensamento algorítmico ao iniciar o curso.
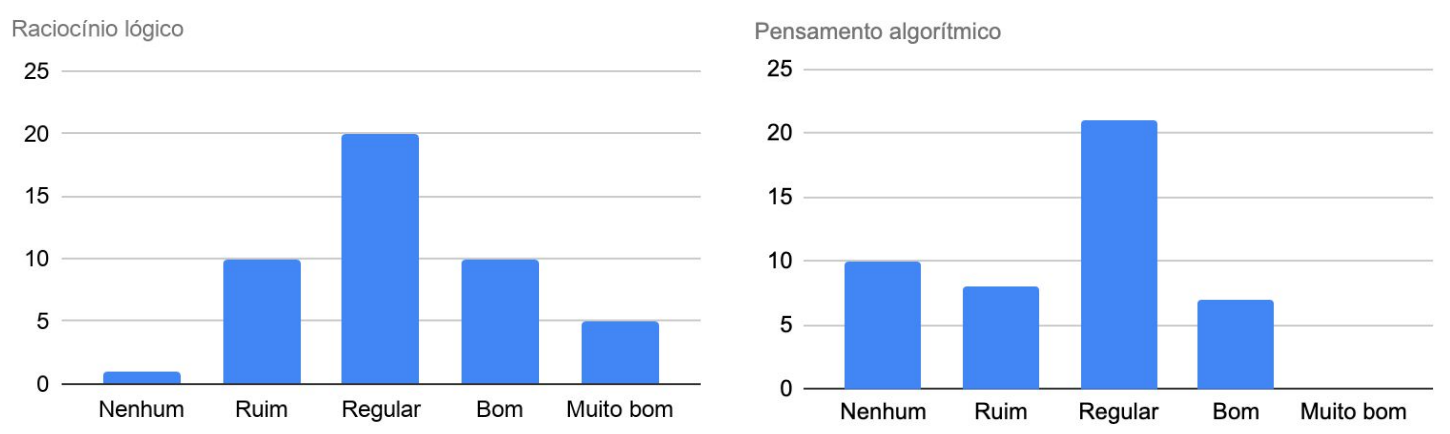

Figura 1: Auto-avaliação dos respondentes sobre seu nível de raciocínio lógico e pensamento algorítmico antes de iniciar o curso de LC

Vinte e cinco (25) respondentes $\mathrm{P} 2$ declararam que se sentiriam mais preparados para cursar Programação se tivessem tido contato com PC antes da disciplina. Destes, um declarou, em campo aberto do questionário: "eu sempre tive muito receio e muito medo de tudo que envolvesse matemática e raciocínio lógico... Comecei a enxergar os desafios lógicos como algo da rotina...".

Nas respostas dos estudantes, percebe-se um otimismo em relação à contribuição do PC para o aprendizado de programação, incluindo questões afetivas. Entretanto, os dois professores de Programação entrevistados ainda não conseguem ver mudanças efetivas no desempenho dos alunos. Estes professores vêm ensinando a disciplina de Programação no curso de LC da UFRPE antes e depois da inserção da disciplina de PC no primeiro período do curso (no segundo semestre de 2018). Como os próprios professores destacaram, dada a mudança recente, ainda é cedo para que eles possam 
avaliar mudanças significativas no desempenho dos estudantes, visto que sempre houve uma variação de desempenho entre turmas. Um dos professores afirmou na entrevista: "eu até perguntei pros próprios alunos o que eles acharam de PC, se contribui de fato com o aprendizado. A maioria até disse que contribui, mas quando vamos ver os resultados... nas notas, eu não vi essa contribuição... Fica a dúvida se realmente contribuiu, eu acredito que é bom, que contribui". O outro professor deu o seguinte depoimento: "meu sentimento é de que com certeza [o PC] ajuda, mas a gente sabe que existe uma retenção maior e dificuldade nesse tipo de conteúdo [de programação]. Eu tenho relatos da primeira turma de PC que agora está em programação que eles estão tendo dificuldades. O meu ponto de vista é esse, [a disciplina de PC] dá mais chances pro aluno ter um caminhar mais fluido, um aprendizado mais sólido... Cada vez mais a gente tem trabalhar não só a parte técnica, mas a motivação também".

Por fim, os professores, assim como vários estudantes, citaram como possível melhoria na disciplina de PC abordar de maneira mais sistemática conteúdos introdutórios de programação, inclusive usando pseudocódigo.

\section{Discussão}

A tendência crescente em desenvolver o pensamento computacional das novas gerações, ancorada no argumento de que se trata de uma habilidade essencial à formação dos cidadãos, vem se refletindo na matriz curricular dos cursos de LC, tanto em termos da formação dos licenciandos para atuar na educação básica com um currículo ampliado de computação, quanto em termos do desenvolvimento do PC dos próprios licenciandos. Esta última vertente, por sua vez, desperta também questões relacionadas a como o desenvolvimento prévio do PC pode facilitar o aprendizado de programação, dada a grande retenção dessa disciplina nos cursos de Computação.

Entretanto, esta vertente traz um risco associado de se reduzir o PC a uma ferramenta para se aprender programação, quando na verdade, programar computadores é apenas uma das competências que podem ser desenvolvidas a partir do PC. O artigo seminal de Wing (2006) já apresentava o PC como uma habilidade analítica para resolução de problemas, em diversas áreas do conhecimento e situações cotidianas. As diretrizes para ensino de Computação na educação básica brasileira definem PC como a "habilidade de compreender, definir, modelar, comparar, solucionar, automatizar e analisar problemas (e soluções) de forma metódica e sistemática" ${ }^{3}$. Assim, embora o PC possa alicerçar a aprendizagem de programação, este não é o seu cerne.

Como autocrítica à presente pesquisa, percebe-se que se induziu professores e estudantes a uma visão reducionista dos objetivos da disciplina de PC nos cursos de LC (percebida claramente nas sugestões de uso de pseudocódigo e foco maior nos conceitos de programação), quando na verdade documentos institucionais apresentam uma expectativa mais ampla. Os Referenciais de Formação para os Cursos de Graduação em Computação da SBC elencam no perfil dos egressos a "capacidade de reconhecer a importância do pensamento computacional na vida cotidiana, como também sua aplicação em outros domínios e ser capaz de aplicá-lo em circunstâncias apropriadas" (ZORZO et al., 2017, p.15). A ementa da disciplina no curso de LC da UFRPE inclui:

\footnotetext{
3 SBC. Diretrizes para ensino de Computação na Educação Básica. 2019. Disponível em: https://www.sbc.org.br/documentos-da-sbc/category/203-educacao-basica
} 
PC na formação do cidadão; estratégias de resolução de problemas com base em lógica algorítmica; prática do PC em cenários interdisciplinares; e métodos e abordagens para integração do PC no ensino básico. Por outro lado, mesmo considerando essa ementa ampla, na nossa visão uma disciplina de PC deveria, ainda assim, facilitar o conseguinte aprendizado de programação.

Levantam-se assim alguns questionamentos. Como estruturar uma disciplina de PC em cursos de LC que contemple os aspectos relacionados à formação do educador, mas que também contribua para a aprendizagem de programação dos licenciandos? Como balancear conteúdos relacionados à compreensão ampla do PC e sua aplicação na educação básica, com competências mais específicas de programação, como o conhecimento de estruturas lógicas como condicionais e laços de repetição? Pensamento Computacional deveria ser, de fato, uma disciplina de primeiro período, pré-requisito de Programação, ou ter seus conteúdos distribuídos transversalmente na matriz do curso?

Ainda que preliminar, a presente pesquisa provoca reflexões importantes relacionadas tanto ao alinhamento do currículo dos cursos de LC às novas diretrizes da SBC para educação básica e aos referenciais de formação para o ensino superior, quanto relacionadas à contribuição do PC para a aprendizagem de programação. Pela limitação na quantidade e diversidade de participantes, trabalhos futuros incluem aumentar a amostragem e o tempo em que esses alunos são acompanhados, ao longo da disciplina.

\section{Referências}

HOED, R. M. Análise da evasão em cursos superiores: o caso da evasão em cursos superiores da área de computação. Dissertação de mestrado, UnB, 2016.

MEC. Diplomação, retenção e evasão nos cursos de graduação em instituições de ensino superior públicas. Comissão Especial de Estudos sobre a Evasão nas Universidades Públicas Brasileiras. ANDIFES / ABRUEM / SESu / MEC. 1996.

MEDEIROS, R. P. Hello, world: uma análise sobre dificuldades no ensino e na aprendizagem de introdução à programação nas universidades. Tese de doutorado, UFPE, 2019.

PONTUAL FALCÃO, T. et al. Currículo da licenciatura em computação: uma proposta alinhada às novas diretrizes e demandas contemporâneas. Anais dos Workshops do Congresso Brasileiro de Informática na Educação - CBIE, 2018.

SBC. Educação Superior em Computação - Estatísticas 2017. Disponível em: https://www.sbc.org.br/documentos-da-sbc/send/133-estatisticas/1200-pdf-png-educ acao-superior-em-computacao-estatisticas-2017

WING, J. M. Computational thinking. Communications of the ACM, v. 49, n. 3, p. 33-35, 2006.

ZORZO, A. et al. Referenciais de formação para os cursos de graduação em computação. Sociedade Brasileira de Computação (SBC). 153p, 2017. 2017. Disponível em: www.sbc.org.br/documentos-da-sbc/category/131-curriculos-de-referencia 